\title{
RISCO MACROECONÔMICO E O MODELO DE CINCO FATORES NO MERCADO ACIONÁRIO BRASILEIRO ${ }^{1}$
}

\author{
Daniel Lucas Martins Portela ${ }^{2}$ \\ Joséte Florencio dos Santos ${ }^{3}$
}

http://dx.doi.org/10.1590/1413-2311.229.86191

\begin{abstract}
RESUMO
Este artigo teve o objetivo de analisar como um fator de risco macroeconômico no modelo de cinco fatores de Fama e French (2015) impacta na explicação dos retornos dos ativos no mercado acionário brasileiro. O modelo de cinco fatores introduziu rentabilidade e investimento como fatores de risco, unindo-se ao prêmio de mercado, tamanho e book-tomarket. Já o fator de risco macroeconômico classifica os ativos em carteiras de acordo com a sua relação entre o crescimento da receita e o crescimento do PIB de mercado. Os dados das demonstrações financeiras e dos retornos dos ativos foram coletados no Economática ${ }^{\circledR}$, no intervalo de julho de 2008 a junho de 2015. Destacam-se como principais resultados a significância estatística das variáveis explicativas na maioria das carteiras, inclusive a variável macroeconômica, com a maioria dos $\mathrm{R}^{2}$ das carteiras variando de 0,400 a 0,709 no modelo de seis fatores.
\end{abstract}

Palavras-chave: Modelo de Cinco Fatores. Rentabilidade. Investimento. Fator de Risco Macroeconômico.

\footnotetext{
${ }^{1}$ Recebido em 26/08/2018, aprovado em 08/10/2018.

${ }^{2}$ Universidade Federal de Pernambuco - Programa de Pós-Graduação em Administração; Recife - PE (Brasil) danielucas10@hotmail.com

${ }^{3}$ Universidade Federal de Pernambuco - Programa de Pós-Graduação em Administração; Recife - PE (Brasil jfs@ufpe.br
} 


\title{
MACROECONOMIC RISK AND FIVE-FACTOR MODEL IN THE BRAZILIAN STOCK MARKET
}

\begin{abstract}
This article aimed to analyze how a macroeconomic risk factor in the Fama and French's five-factor model (2015) impacts on the explanation of the returns of assets in the Brazilian stock market. The five-factor model introduced profitability and investment as risk factors, joining the market premium, size and book-to-market. The macroeconomic risk factor, however, classifies the assets in portfolios according to their relationship between revenue growth and market GDP growth. Data on financial statements and asset returns were collected in Economática ${ }^{\circledR}$ from July 2008 to June 2015. The main results are the statistical significance of the explanatory variables in most portfolios, including the macroeconomic variable, with most of the $\mathrm{R}^{2}$ of the portfolios ranging from 0.400 to 0.709 in the six-factor model.
\end{abstract}

Key-words: Five-Factor Model. Profitability. Investment. Macroeconomic Risk Factor.

\section{RIESGO MACROECONÓMICO Y EL MODELO DE LOS CINCO FACTORES EN EL MERCADO DE ACCIONES BRASILEÑO}

\section{RESUMEN}

Este artículo tuvo el objetivo de analizar cómo un factor de riesgo macroeconómico en el modelo de cinco factores de Fama y French (2015) impacta en la explicación de los retornos de los activos en el mercado accionario brasileño. El modelo de cinco factores introdujo rentabilidad e inversión como factores de riesgo, uniéndose al premio de mercado, tamaño y book-to-market. El factor de riesgo macroeconómico clasifica los activos en carteras de acuerdo con su relación entre el crecimiento de los ingresos y el crecimiento del PIB de mercado. Los datos de los estados financieros y de los retornos de los activos fueron recolectados en el Economática ${ }^{\circledR}$, en el intervalo de julio de 2008 a junio de 2015. Se destacan como principales resultados la significancia estadística de las variables explicativas 
en la mayoría de las carteras, incluyendo la variable macroeconómica, la mayoría de los $\mathrm{R}^{2}$ de las carteras variando de 0,400 a 0,709 en el modelo de seis factores.

Palabras-clave: Modelo de cinco factores. Rentabilidad. Inversión. Factor de Riesgo Macroeconómico.

\section{INTRODUÇÃO}

Harry Markowitz (1952) estabeleceu a relação entre risco e retorno na seleção de carteiras feita pelos investidores. Para o autor, o objetivo do investidor seria buscar a maximização dos retornos a um dado nível de risco ou a minimização deste a um dado nível de retorno. Dessa forma, haveria uma carteira de mercado que maximiza o retorno e minimiza o risco, denominada de carteira eficiente. Sharpe (1964), Lintner (1965) e Black (1972) desenvolveram quase paralelamente o Capital Asset Pricing Model (CAPM) que teve como objetivo estudar a relação entre risco e retorno. Um incremento no retorno só poderia ocorrer quando o mesmo incorre em mais risco, havendo, então, uma relação linear entre essas duas variáveis, ou seja, o retorno esperado e uma medida de risco sistemático. Assim, pelo CAPM, o retorno de uma carteira pode ser medido com a utilização do ativo livre de risco do mercado, sensibilidade da carteira do investidor em relação à carteira de mercado e a carteira de mercado, de modo que a carteira de mercado de Sharpe pode ser representada como uma síntese da fronteira de carteiras eficientes do mercado no trabalho de Markowitz.

Contudo, para Fama e French - FF (1992; 1993), a relação entre as carteiras do mercado e os fatores de risco não era baseada em um só fator, sendo assim, desenvolveram um modelo de três fatores de risco para que as variações dos retornos em excesso do mercado pudessem ser melhor explicadas. Os três fatores foram o prêmio de mercado, o tamanho da empresa e a relação entre valor de mercado/valor contábil (book-to-market). Tal modelo melhorou significativamente a explicação das variações dos retornos e sua metodologia de construção de carteiras conseguiu captar os fatores de risco no mercado. Após tal estudo, Carhart (1997), utilizando o fator momento de Jegadeesh e Titman (1993), desenvolveu um modelo com quatro fatores que aliado ao modelo de FF (1993) avançou na literatura financeira ao explicar os retornos do mercado.

Mais recentemente, FF (2015) perceberam que o modelo de três fatores poderia ser aprimorado. Os autores introduziram a rentabilidade e o investimento como fatores de risco, conforme sugestão de Hou, Xue e Zhang (2015) e Novy-Marx (2013), no modelo de três 
fatores, desenvolvendo então um modelo de cinco fatores de risco. Após realizarem testes empíricos, FF (2015) confirmaram a superioridade do modelo, visto que suas variáveis explicam boa parte das variações dos retornos em excesso das carteiras de investimento.

Este estudo sugere então a adição de um fator de risco macroeconômico, que relaciona o crescimento da receita das empresas com o crescimento do PIB de mercado, ao modelo de cinco fatores de FF (2015), criando um modelo de seis fatores de risco. Verifica-se que Fama (1990) já ressaltava que os retornos dos ativos tinham relação com a atividade econômica. Por sua vez, Dimson, Marsh e Staunton (2003) e Ritter (2005) também confirmam a relação entre os retornos dos ativos e o crescimento do produto, porém sua análise deve ser cautelosa, visto que na análise dos autores tal relação foi negativa, sendo assim a construção de um fator de risco, baseado na metodologia de FF $(1992,1993)$ pode ajudar a entender essa relação.

Torna-se então necessário estudar se o comportamento dos ativos no mercado nacional também é melhor explicado por esse modelo de cinco fatores, com a inclusão da rentabilidade e investimento entre as suas variáveis, além de adicionar o fator de risco macroeconômico. Sendo assim, este artigo tem o objetivo de analisar se as variações dos retornos dos ativos no mercado brasileiro são melhor explicadas com um modelo de seis fatores de risco, baseado no modelo de cinco fatores de FF (2015) e um fator de risco macroeconômico.

Este artigo está dividido em seis seções. Na primeira, esta introdução; em seguida, um referencial teórico sobre o modelo de cinco fatores de FF (2015) e a relação entre os retornos dos ativos e a atividade econômica; os procedimentos metodológicos; a análise dos resultados; as conclusões e as referências.

\section{REFERENCIAL TEÓRICO}

\subsection{MODELO DE CINCO FATORES DE FAMA E FRENCH (2015)}

FF (2015) explicam que o preço das ações parte do valor descontado dos dividendos futuros esperados para um ativo, pelo modelo de desconto de dividendos. Tal modelo pode fornecer uma relação entre rentabilidade e investimento e os retornos das ações, já que lucros mais elevados no futuro podem desencadear retornos esperados maiores também. A relação com o investimento está no fato de que, quando o valor de mercado e o valor contábil são fixos, maior crescimento no investimento implica em menor rentabilidade. Tais variáveis estão relacionadas com o book-to-market, já que o valor de mercado da ação também responde a variações em previsões de lucros e investimentos divulgadas pela companhia. 
Assim, FF (2015) adicionaram os fatores rentabilidade e investimento ao modelo de três fatores (Fama \& French, 1993), desenvolvendo então um modelo de cinco fatores.

Visto a lacuna ainda presente no modelo anterior (Fama \& French, 1993) e havendo evidências de trabalhos anteriores (Novy-Marx, 2013; HOU et al., 2015) que identificam a relação entre os retornos dos ativos e essas novas variáveis, os autores resolveram analisar tais fatores com o modelo de 1993. Esses novos elementos foram conhecidos como rentabilidade (Robust Minus Weak - RMW) e o nível de investimento da empresa (Conservative Minus Agressive - CMA). Sendo assim, o então modelo de cinco fatores de FF (2015) corresponde:

$$
R_{\mathrm{it}}-R_{F t}=a_{\mathrm{i}}+b_{\mathrm{i}}\left(R_{M t}-R_{F \mathrm{t}}\right)+s_{\mathrm{i}} S M B_{\mathrm{t}}+h_{\mathrm{i}} H M L_{\mathrm{t}}+r_{\mathrm{i}} R M W_{\mathrm{t}}+c_{\mathrm{i}} C M A_{\mathrm{t}}+e_{\mathrm{it}}
$$

Onde:

$\mathrm{R}_{\text {it }}=$ retorno do ativo no tempo $\mathrm{t}$

$\mathrm{R}_{\mathrm{Ft}}=$ retorno do ativo livre de risco no tempo $\mathrm{t}$

$\mathrm{R}_{\mathrm{Mt}}=$ retorno médio da carteira de mercado no tempo $\mathrm{t}$

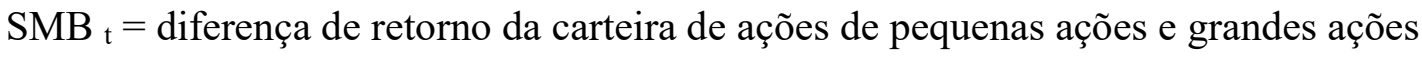

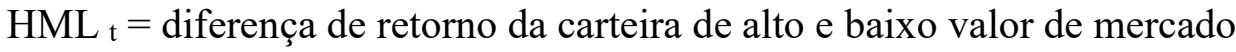

$\mathrm{RMW}_{\mathrm{t}}=$ diferença de retorno da carteira de robusta e baixa rentabilidade

$\mathrm{CMA}_{\mathrm{t}}=$ diferença de retorno da carteira de alto e baixo investimento

$\mathrm{a}_{\mathrm{i}}=$ intercepto para todas as carteiras $\mathrm{i}$

$\mathrm{e}_{\text {it }}=$ valor residual de média zero

$\mathrm{Na}$ análise empírica desse modelo nos Estados Unidos, FF (2015) utilizaram 25 carteiras e separaram em quintis, utilizando as ações da NYSE, Amex e Nasdaq, entre 1963 e 2013. Os autores identificaram a presença do efeito tamanho, onde o retorno médio cai de pequenas para grandes ações; o efeito valor de mercado, onde o retorno médio aumenta à medida que aumenta a relação book-to-market; foi identificado também o efeito rentabilidade apontado por Novy-Marx (2013). Já no caso de pequenas ações, há evidências dos efeitos de valor de mercado, rentabilidade e investimento, onde a relação com rentabilidade é positiva e com o investimento é negativa. Vale salientar também que o modelo de cinco fatores diminui a variância inexplicada do modelo de três fatores, chegando em alguns casos a ter menos de $10 \%$ de variação sem explicação. 


\subsection{OS RETORNOS DOS ATIVOS, A ATIVIDADE ECONÔMICA E O CRESCIMENTO}

DO PIB

Para Fama (1990), as relações entre os retornos dos ativos e as variáveis macroeconômicas podem ser explicadas devido as informações futuras que podem refletir nos retornos atuais; mudanças nas taxas de desconto afetam os preços das ações e investimento real; e mudanças nos preços que afetam a demanda por bens de consumo e investimento. Tal ligação pode ser então identificada por meio do modelo de fluxo de caixa descontado. Essa conexão parte da mensuração do valor dos ativos da empresa, que leva os investidores ao modelo de fluxo de caixa, o qual é o cálculo do valor presente esperado dos dividendos da empresa, de acordo com a taxa de desconto definida pelo investidor. Visto que essa taxa flutua de acordo com a realidade do mercado, ou seja, com as expectativas e previsões do mercado acerca da realidade futura da economia, sua presença impacta, assim, na definição das taxas de desconto atuais e consequentemente o valor presente do fluxo de caixa, já que são essas taxas que precificam os fluxos de caixa das firmas (Fama, 1990).

Desse modo, a construção dos preços das ações no mercado reflete essas expectativas futuras da economia, como também o valor da empresa. Sendo assim, optou-se pela utilização do crescimento do PIB como fator de risco aliado ao mercado acionário, apesar de que para Dimson et al. (2003), os retornos dos ativos estão ligados ao crescimento do PIB de forma negativa, ou seja, a correlação entre os retornos dos ativos e o crescimento do produto no longo prazo foi negativa. Ritter (2005) corroborou com a conclusão de Dimson et al. (2003), já que ele encontrou uma correlação negativa $(-0,37)$ entre o retorno real composto sobre as ações e a variação de crescimento real do PIB per capita. A explicação para a correlação negativa pode vir do comportamento dos investidores, onde investir em mercados com crescimento esperado alto os atrai, que fazem ofertas acima dos preços das ações, diminuindo os retornos delas, já que os dividendos serão os mesmos. Ritter (2005) ainda ressalta que o crescimento econômico aumenta o padrão de vida dos consumidores e não necessariamente aumenta o valor presente dos dividendos das empresas e os retornos das ações dependem disso. O crescimento econômico é gerado por meio de mudanças tecnológicas e capital para as empresas, mas isso também não gera mudanças nos dividendos por ação, não beneficiando diretamente os proprietários do capital.

Além disso, Wade e May (2013) acreditam que essa relação deveria ser vista com a inclusão de um contexto econômico maior, como por exemplo juntamente com a inflação e política monetária. Eles identificaram uma relação existente entre o crescimento do PIB e os 
retornos dos ativos ao separarem os períodos em ciclos econômicos de desaceleração, recessão, recuperação e expansão. Dessas quatro fases da economia, os autores encontraram que apenas na fase de recessão os retornos dos ativos não encontraram relação significativa, já que nesta fase, enquanto a economia cai, os retornos ainda continuam a ser positivos.

Mladina (2016) concorda com Wade e May (2013) quanto ao crescimento esperado do PIB, indicando que os mercados podem incorporar as expectativas de crescimento futuro de maneira rápida aos preços dos ativos de forma que os investidores não sejam capazes de se beneficiar disso. Ao relacionar ambas as variáveis com períodos iguais, o autor não encontrou coeficientes significativos, mas quando observou os retornos dos ativos com a expectativa de crescimento do PIB para o ano seguinte, o autor identificou regressões com coeficiente significativo e $\mathrm{R}^{2}$ de $25 \%$, indicando uma relação existente entre essas variáveis.

Observa-se então que a relação entre os retornos e o crescimento do PIB é variável ao longo do tempo de acordo com o ciclo econômico; há relação significativa entre os retornos atuais e a expectativa de crescimento do PIB futuro; e as expectativas de crescimento do PIB futuro parecem já estar incorporadas aos retornos visto que quando essas expectativas mudam, os retornos dos ativos também se modificam. Sendo assim, entende-se que a inclusão de um fator de risco macroeconômico que possa identificar a variação dos retornos, ou melhor, parte da variação dos retornos, seja compatível com os estudos já realizados nessa área, já que para Ritter (2005) também não há consenso entre como estimar os retornos futuros das ações.

\section{PROCEDIMENTOS METODOLÓGICOS}

\subsection{CARACTERIZAÇÃO DA PESQUISA E COLETA DE DADOS}

O estudo propõe-se a analisar os fatos sob a ótica de dados em séries temporais, onde eles são coletados em vários instantes no tempo (Gujarati \& Porter, 2008), comparando os resultados da análise do Brasil com os estudos internacionais. A população utilizada foi composta de empresas de capital aberto do Brasil, no período de julho de 2008 a junho de 2015. Foram realizadas as seguintes exclusões de empresas da amostra como empresas financeiras, já que possuem características diferenciadas de endividamento; empresas com patrimônio líquido nulo ou negativo; ações com dados faltantes, em período superior a um ano consecutivo; eventuais outliers pertencentes à amostra; e ações de empresas sem valor de mercado nos períodos de fim de exercício, semelhante à metodologia de Mussa, Famá e Dos Santos (2012) e Noda, Martelanc e Kayo (2016).

REAd | Porto Alegre - Vol. 24 - No 3 - Setembro / Dezembro 2018 - p. 269-293 
A análise de dados foi secundária, com o banco de dados do Economática ${ }^{\circledR}$, em relação aos dados de preço de fechamento das ações das empresas, quantidade de ações ao final de cada exercício, valor do índice de mercado de cada bolsa de valores e demonstrações contábeis das empresas. Foram utilizados também os dados do Instituto Brasileiro de Geografia e Estatística - IBGE. A periodicidade do cálculo dos retornos das ações foi mensal e os dados e testes econométricos utilizados para análise foram realizados no Microsoft Excel 2013 e no STATA® na versão 12.

\subsection{DESCRIÇÃO DAS VARIÁVEIS E MODELAGEM ECONOMÉTRICA}

Procedeu-se à construção de uma variável macroeconômica que se denominou de “Crescimento em Relação ao PIB”. Evidências encontradas em estudos anteriores (Fama, 1990; Schwert, 1990) relacionam os retornos dos ativos e a atividade econômica por meio das taxas de desconto e do fluxo de caixa descontado das empresas. Optou-se então por analisar a relação entre os retornos dos ativos e crescimento do PIB, semelhante à de FF $(1993 ; 2015)$, permitindo classificar os ativos e separá-los em carteiras de investimentos. A utilização da receita bruta das empresas pode ser corroborada pela análise de Andrade e Melo (2016), onde ao estudar as empresas agropecuárias brasileiras, os autores encontraram relação significativa entre o PIB e as receitas brutas das companhias. Se o PIB e a receita estão intimamente ligados, pode-se esperar que o fator de risco que combine essas duas variáveis seja aceitável e possa capturar variações dos retornos das ações, conforme fórmula:

$$
\text { Fator Crescimento sobre } P I B_{t}=\frac{\left(\frac{W B V_{p}}{W B V_{[-1}}-1\right)-I N F_{t}}{\left(\frac{P W B_{p}}{W W W_{L-1}}-1\right)-I N F_{t}}
$$

Onde:

$$
\begin{aligned}
& \mathrm{RBV}_{\mathrm{t}}=\text { receita bruta de vendas da empresa no tempo } t \\
& \mathrm{RBV}_{\mathrm{t}-1}=\text { receita bruta de vendas da empresa em } \mathrm{t}-1 \\
& \mathrm{PIB}_{\mathrm{t}}=\text { produto interno bruto no tempo } \mathrm{t} \\
& \mathrm{PIB}_{\mathrm{t}-1}=\text { produto interno bruto no tempo } \mathrm{t}-1 \\
& \mathrm{INF}_{\mathrm{t}}=\text { inflação no tempo } \mathrm{t}
\end{aligned}
$$

A empresa com valores altos dessa métrica possuía um rápido crescimento de receita em relação ao crescimento do PIB do mercado como um todo, sendo então classificada como empresa Fast; já para um valor baixo dessa métrica, a empresa possuía um crescimento lento REAd | Porto Alegre - Vol. 24 - No 3 - Setembro / Dezembro 2018 - p. 269-293 
de receita em relação ao crescimento do PIB de mercado como um todo, sendo então classificada como Slow. A variável seria então calculada pela diferença entre os retornos das empresas Fast e das empresas Slow, ou seja, Fast Minus Slow, o fator macroeconômico FMS. No caso dos retornos das ações, o retorno será calculado apenas pela ação com a maior disponibilidade de dados, sendo ainda deflacionados pelo IGP-DI, no caso do Brasil. As variáveis utilizadas para a análise do modelo e a metodologia de cálculo são apresentadas no

Quadro 1.

\section{Quadro 1 - Descrição das variáveis utilizadas}

Este quadro apresenta a construção das variáveis que foram utilizadas na análise, que são tamanho (SMB), book-to-market (HML), rentabilidade (RMW), investimento (CMA) e crescimento (FMS).

\begin{tabular}{|c|c|l|}
\hline Sigla & Variável & \multicolumn{1}{c|}{ Descrição } \\
\hline VM & Valor de Mercado & Multiplicação do número de ações pelo seu preço de mercado no tempo t \\
\hline RC & Retorno da Carteira & $\begin{array}{l}\text { Média ponderada dos retornos das ações pelo valor de mercado para } \\
\text { identificar as estratégias de cada fator de risco }\end{array}$ \\
\hline VC & Valor Contábil & Valor do Patrimônio Líquido no Balanço Patrimonial no período t \\
\hline RM & Retorno de Mercado & Retorno do índice de mercado, no caso será o Ibovespa da BM\& Bovespa \\
\hline R $_{F}$ & $\begin{array}{c}\text { Retorno do Ativo } \\
\text { Livre de Risco }\end{array}$ & $\begin{array}{l}\text { Retorno do título livre de risco, sendo utilizada a taxa de variação da } \\
\text { caderneta de poupança }\end{array}$ \\
\hline TAM & Tamanho & Grupos divididos pelo tamanho em termos de valor de mercado da empresa \\
\hline B/M & Book-to-Market & Valor contábil de ações em t-1 dividido pelo valor de mercado em t-1 \\
\hline REN & Rentabilidade & $\begin{array}{l}\text { Receita menos o CMV, despesas com juros e vendas, despesas gerais e } \\
\text { despesas administrativas em t, divididos pelo patrimônio líquido }\end{array}$ \\
\hline INV & Investimento & Divisão da variação dos ativos totais em t e ativos totais em t-1 \\
\hline PIB & Produto Interno Bruto & Variação do PIB, divulgado pelo IBGE \\
\hline INF & Inflação & Variação da inflação oficial, divulgada pelo IBGE \\
\hline
\end{tabular}

Fonte: adaptado de Mussa et al. (2012), FF (2015), Noda et al. (2016).

De posse das metodologias de cálculo das variáveis, procedeu-se a modelagem econométrica onde são percebidas as regressões que foram utilizadas nos modelos de cinco e seis fatores de risco, conforme equações abaixo: 


$$
\begin{gathered}
R_{i t}-R_{F t}=a_{i}+b_{i}\left(R_{M t}-R_{F t}\right)+s_{i} S M B_{t}+h_{i} H M L_{t}+ \\
r_{i} R M W_{t}+c_{i} C M A_{t}+e_{i t} \\
R_{i t}-R_{F t}=a_{i}+b_{i}\left(R_{M t}-R_{F t}\right)+s_{i} S M B_{t}+h_{i} H M L_{t}+ \\
r_{i} R M W_{t}+f_{i} F M S_{t}+e_{i t} \\
R_{i t}-R_{F t}=a_{i}+b_{i}\left(R_{M t}-R_{F t}\right)+s_{i} S M B_{t}+h_{i} H M L_{t}+ \\
c_{i} C M A_{t}+f_{i} F M S_{t}+e_{i t} \\
R_{i t}-R_{F t}=a_{i}+b_{i}\left(R_{M t}-R_{F t}\right)+s_{i} S M B_{t}+h_{i} H M L_{t}+ \\
r_{i} R M W_{t}+c_{i} C M A_{t}+f_{i} F M S_{t}+e_{i t}
\end{gathered}
$$

Onde:

$\mathrm{R}_{\text {it }}=$ retorno do ativo no tempo $\mathrm{t}$

$\mathrm{R}_{\mathrm{Ft}}=$ retorno do ativo livre de risco no tempo $\mathrm{t}$

$\mathrm{R}_{\mathrm{Mt}}=$ retorno médio da carteira de mercado no tempo $\mathrm{t}$

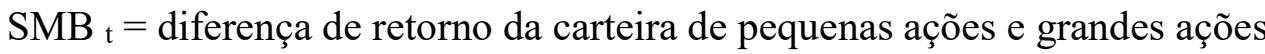

$\mathrm{HML}_{\mathrm{t}}=$ diferença de retorno da carteira de alto e baixo valor de mercado

$\mathrm{RMW}_{\mathrm{t}}=$ diferença de retorno da carteira de robusta e baixa rentabilidade

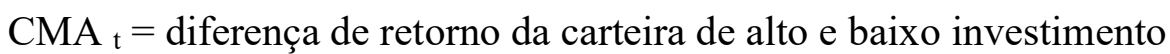

$\mathrm{FMS}_{\mathrm{t}}=$ diferença de retorno da carteira de alto e baixo crescimento

$\mathrm{a}_{\mathrm{i}}=$ intercepto para todas as carteiras $\mathrm{i}$

$\mathrm{e}_{\text {it }}=$ valor residual de média zero

Sendo assim, a variável dependente é o retorno da carteira, que é calculado a partir dos retornos das ações das empresas que compõem cada um dos grupos e as variáveis independentes são SMB, HML, RMW, CMA, R $\mathrm{R}_{\mathrm{M}} \mathrm{R}_{\mathrm{F}}$ (retorno de mercado) e FMS.

\subsection{FORMAÇÃO DAS CARTEIRAS}

As carteiras foram então escalonadas ordinalmente e particionadas de maneira semelhante aos outros estudos de FF (1993; 2015). Foram então realizadas duas classificações, na primeira dividiu-se os ativos em quatro grupos por fator de risco, cada um dos quatro grupos com $25 \%$ do total do número de ativos. Em seguida, construiu-se 16 carteiras relacionando os retornos em excesso de acordo com essa divisão, nos painéis da Tabela 3. Já na segunda classificação, os ativos foram classificados em dois grupos por fator 
de risco, e, em seguida, foram alocados em 32 carteiras, sendo separados pela mediana da quantidade de ativos no período da classificação.

A primeira classificação das carteiras foi realizada com o objetivo de ter uma análise visual e clara das diferenças dos retornos entre os grupos de acordo com os fatores de risco. Já a segunda classificação foi utilizada para a construção dos fatores de risco e para utilização nesses dados nas regressões. Se são utilizados 5 fatores de classificação e em cada fator temse 2 grupos, foram $2 \times 2 \times 2 \times 2 \times 2$ carteiras, no total de 32 carteiras, sendo evidenciada com todas as carteiras $\mathrm{C} 1$ a C32, conforme Quadro 2.

\section{Quadro 2 - Descrição das carteiras}

Este quadro apresenta como foram construídas as 32 carteiras de acordo com a separação das ações das empresas, conforme os critérios de tamanho (SMB), book-to-market (HML), rentabilidade (RMW), investimento (CMA) e crescimento (FMS). As definições desses critérios podem ser visualizadas nesta mesma seção.

\begin{tabular}{|c|c|c|c|c|c|c|c|c|c|c|c|}
\hline Carteira & Tam. & BTM & Rent. & Investimento & Cresc. & Cart. & Tam. & BTM & Rent. & \begin{tabular}{|l|} 
Investimento \\
\end{tabular} & Cresc. \\
\hline C1 & $\mathrm{S}$ & $\mathrm{H}$ & R & $\bar{C}$ & $F$ & C17 & $\bar{S}$ & $\overline{\mathrm{H}}$ & $\bar{R}$ & $\bar{C}$ & $\mathrm{Sl}$ \\
\hline C2 & $\mathrm{S}$ & $\mathrm{H}$ & $\mathrm{R}$ & A & $\mathrm{F}$ & C18 & $\mathrm{S}$ & $\mathrm{H}$ & $\mathrm{R}$ & A & $\mathrm{Sl}$ \\
\hline $\mathrm{C3}$ & $\mathrm{S}$ & $\mathrm{H}$ & $\overline{\mathrm{W}}$ & $\bar{C}$ & $F$ & \begin{tabular}{|l|} 
C19 \\
\end{tabular} & $\mathrm{S}$ & $\mathrm{H}$ & $\overline{\mathrm{W}}$ & $\bar{C}$ & S1 \\
\hline C4 & $S$ & $\mathrm{H}$ & $\mathrm{W}$ & $\bar{A}$ & $F$ & $\mathbf{C 2 0}$ & $S$ & $\overline{\mathrm{H}}$ & $\bar{W}$ & $\bar{A}$ & $\mathrm{Sl}$ \\
\hline C5 & $\mathrm{S}$ & $\bar{L}$ & $\mathrm{R}$ & $\bar{C}$ & $\mathrm{~F}$ & C21 & $\bar{S}$ & $\bar{L}$ & $\mathrm{R}$ & $\bar{C}$ & $\mathrm{Sl}$ \\
\hline C6 & $\mathrm{S}$ & $\mathrm{L}$ & $\mathrm{R}$ & A & $F$ & \begin{tabular}{|l|}
$\mathbf{C 2 2}$ \\
\end{tabular} & $\mathrm{S}$ & $\mathrm{L}$ & $\mathrm{R}$ & A & Sl \\
\hline $\mathrm{C} 7$ & $\mathrm{~S}$ & $\mathrm{~L}$ & $\mathrm{~W}$ & $\mathrm{C}$ & $\mathrm{F}$ & $\mathbf{C 2 3}$ & $\mathrm{S}$ & $\mathrm{L}$ & $\mathrm{W}$ & $\mathrm{C}$ & $\mathrm{Sl}$ \\
\hline C8 & $\mathrm{S}$ & $\bar{L}$ & $\mathrm{~W}$ & $\mathrm{~A}$ & $\mathrm{~F}$ & \begin{tabular}{|l|} 
C24 \\
\end{tabular} & $\mathrm{S}$ & $\bar{L}$ & $\mathrm{~W}$ & $\mathrm{~A}$ & $\mathrm{~S} 1$ \\
\hline C9 & $\mathrm{B}$ & $\mathrm{H}$ & $\mathrm{R}$ & $\mathrm{C}$ & $\mathrm{F}$ & \begin{tabular}{|l|}
$\mathbf{C 2 5}$ \\
\end{tabular} & $\mathrm{B}$ & $\mathrm{H}$ & $\mathrm{R}$ & $\mathrm{C}$ & $\mathrm{Sl}$ \\
\hline C10 & $\mathrm{B}$ & $\mathrm{H}$ & $\mathrm{R}$ & $\mathrm{A}$ & $\mathrm{F}$ & $\mathrm{C26}$ & $\mathrm{B}$ & $\mathrm{H}$ & $\bar{R}$ & $\mathrm{~A}$ & Sl \\
\hline C11 & $\mathrm{B}$ & $\mathrm{H}$ & $\overline{\mathrm{W}}$ & $\mathrm{C}$ & $F$ & \begin{tabular}{|l|}
$\mathbf{C 2 7}$ \\
\end{tabular} & $\mathrm{B}$ & $\mathrm{H}$ & $\overline{\mathrm{W}}$ & $\mathrm{C}$ & $\mathrm{Sl}$ \\
\hline $\mathrm{C12}$ & $\mathrm{B}$ & $\mathrm{H}$ & $\overline{\mathrm{W}}$ & $\mathrm{A}$ & $F$ & \begin{tabular}{|l|}
$\mathbf{C 2 8}$ \\
\end{tabular} & $\mathrm{B}$ & $\mathrm{H}$ & $\mathrm{W}$ & A & $\mathrm{Sl}$ \\
\hline $\mathrm{C13}$ & $\mathrm{B}$ & $\mathrm{L}$ & $\mathrm{R}$ & $\mathrm{C}$ & $F$ & C29 & $\mathrm{B}$ & $\mathrm{L}$ & $\mathrm{R}$ & $\mathrm{C}$ & $\mathrm{Sl}$ \\
\hline C14 & $\mathrm{B}$ & $\mathrm{L}$ & $\mathrm{R}$ & $\mathrm{A}$ & $\mathrm{F}$ & C30 & $\mathrm{B}$ & $\mathrm{L}$ & $\mathrm{R}$ & $\mathrm{A}$ & $\mathrm{Sl}$ \\
\hline C15 & $\mathrm{B}$ & $\mathrm{L}$ & $\mathrm{W}$ & $\bar{C}$ & $F$ & C31 & B & $\mathrm{L}$ & $\mathrm{W}$ & $\bar{C}$ & $\mathrm{Sl}$ \\
\hline $\mathrm{C16}$ & B & $\mathrm{L}$ & $\mathrm{W}$ & $\mathrm{A}$ & $\mathrm{F}$ & C32 & B & $\mathrm{L}$ & $\mathrm{W}$ & $\mathrm{A}$ & $\mathrm{S} 1$ \\
\hline
\end{tabular}

Onde: $\mathrm{S}=$ Small $; \mathrm{B}=$ Big $; \mathrm{H}=$ High $; \mathrm{L}=$ Low $; \mathrm{R}=$ Robust $; \mathrm{W}=$ Weak $; \mathrm{C}=$ Conservative $; \mathrm{A}=$ Agressive $; \mathrm{F}=$ Fast $; \mathrm{Sl}=$ Slow. Fonte: elaborado pelo autor.

De posse das informações da seção anterior, observam-se as variáveis que serão utilizadas para análise, como também a obtenção dos retornos anormais das carteiras, que no caso foram as variáveis independentes da regressão, serão obtidas por meio da diferença entre os retornos médios das carteiras de acordo com a sua classificação nos 32 grupos. $O$ fator de risco macroeconômico seguiu a mesma metodologia de FF (1993; 2015), com a diminuição dos retornos das carteiras do tipo Fast menos Slow. Em seguida, será mostrada a análise dos dados e os resultados com uma estatística descritiva e análise multivariada por meio da regressão de FF (2015), como forma de avaliar a relação entre as variáveis. 


\section{ANÁLISE DE DADOS E RESULTADOS}

\subsection{ESTATÍSTICA DESCRITIVA}

O total de empresas analisadas foram 180, com um valor de mercado total que ultrapassa R\$ 1 trilhão na maioria dos anos estudados. As 180 empresas presentes na amostra estão distribuídas em 11 subsetores, sendo os setores mais representativos os setores de Consumo Cíclico (45), Utilidade Pública (32) e Bens Industriais (29). As 32 carteiras formadas com os fatores de risco tiveram uma média dos retornos em excesso de 0,022 , o valor de mercado médio das carteiras em $\mathrm{R} \$ 44$ bilhões e número de ações média em 4 . Sobre os fatores de risco, obteve-se 84 observações, referentes aos meses de análise dos dados. A Tabela 1 ilustra a estatística descritiva desses fatores, onde se vê que as diferenças de retorno médias positivas ficam para os fatores SMB, HML e CMA, já os demais obtiveram essas diferenças negativas. Pode-se verificar que os fatores com maior variação são os fatores SMB e CMA, já em relação à amplitude, observa-se que SMB foi o que apresentou a maior delas, conforme Tabela 1 .

\section{Tabela 1 - Estatística Descritiva dos Fatores de Risco}

Esta tabela apresenta as estatísticas descritivas para as variáveis estudadas, que são tamanho (SMB), book-tomarket (HML), prêmio de mercado $\left(\mathrm{R}_{\mathrm{M}}-\mathrm{R}_{\mathrm{F}}\right)$, rentabilidade (RMW), investimento (CMA) e crescimento (FMS). As definições das variáveis características das empresas podem ser visualizadas na seção 2.2.

\begin{tabular}{crrrrrr}
\hline Fatores de Risco & \multicolumn{1}{l}{ SMB } & \multicolumn{1}{l}{ HML } & \multicolumn{1}{c}{ RM-RF $_{\mathbf{F}}$} & \multicolumn{1}{l}{ RMW } & \multicolumn{1}{c}{ CMA } & \multicolumn{1}{c}{ FMS } \\
\hline N & 84 & 84 & 84 & 84 & 84 & 84 \\
Média & 0,069 & 0,022 & $-0,006$ & $-0,038$ & 0,092 & $-0,018$ \\
Desvio Padrão & 0,517 & 0,470 & 0,065 & 0,457 & 0,528 & 0,488 \\
Mínimo & $-1,437$ & $-1,596$ & $-0,256$ & $-1,773$ & $-1,134$ & $-1,500$ \\
Máximo & 1,751 & 0,920 & 0,150 & 0,831 & 2,177 & 1,683 \\
\hline
\end{tabular}

Fonte: elaborado pelo autor.

Em relação ao trabalho de FF (2015), todos os fatores de risco tiveram a média dos retornos em excesso positivas, diferentemente desta. Salienta-se a diferença em relação à quantidade de meses da amostra é muito grande, onde na americana foram 606 meses, enquanto nesta pesquisa são 84 meses. Dadas as diversas simulações, as estatísticas descritivas dos fatores de risco de FF (2015) foram mais constantes para o fator tamanho e para os outros fatores dependem e variam de acordo com a construção das carteiras.

\subsection{ANÁLISE DO MODELO}

Para melhor visualizar as diferenças entre os retornos dos ativos, optou-se por realizar uma análise semelhante à de FF (2015), com a distribuição dos ativos em 25 carteiras, sendo 
evidenciadas em matrizes com a alocação de dois fatores por vez. Com a introdução do fator macroeconômico crescimento no modelo original, optou-se então pela distribuição dos ativos em 32 carteiras, classificadas de acordo com a mediana da quantidade dos ativos referentes a cada período. Sendo assim, a construção dos fatores de risco e as regressões realizadas foram feitas com os valores referentes à classificação dos ativos nas 32 carteiras. Foram comprovadas a estocasticidade das variáveis independentes em relação à variável dependente, por meio da correlação de Pearson; o teste de Durbin-Watson; o teste de Teste de Kolmogorov-Smirnov (K-S) e a média dos resíduos das regressões; o Teste de BreuschPagan; e a estatística VIF. Sendo assim, pode-se inferir que o método de regressão linear múltipla sugerido é válido para a análise.

\subsubsection{Relação entre os fatores de risco e os retornos em excesso das carteiras de investimentos}

$\mathrm{Na}$ Tabela 2, observa-se a matriz de correlação de Pearson entre os seis fatores de risco. Vê-se que a maior correlação é entre o fator prêmio de mercado e CMA $(-0,547)$, podese então inferir que partes dos fatores correspondem às mesmas variações dos retornos. Além destas, foram identificadas correlações significativas entre o prêmio com todos os fatores de risco, tamanho $(-0,241)$, book-to-market $(0,357)$, rentabilidade $(-0,290)$ e crescimento $(0,369)$.

Tabela 2 - Matriz de Correlação de Pearson entre os Fatores de Risco

As variáveis estudadas foram o tamanho (SMB), o book-to-market (HML), o prêmio de mercado $\left(\mathrm{R}_{\mathrm{M}}-\mathrm{R}_{\mathrm{F}}\right)$, a rentabilidade (RMW), o investimento (CMA) e o crescimento (FMS). As definições das variáveis características das empresas podem ser visualizadas na seção 2.2. Esta tabela apresenta a matriz das correlações entre as variáveis, das quais são consideradas as regressões lineares com dados em série temporal.

\begin{tabular}{crrrrrr}
\hline Fatores de Risco & \multicolumn{1}{c}{ SMB } & \multicolumn{1}{c}{ HML } & \multicolumn{1}{c}{$\mathbf{R}_{\mathbf{M}-\mathbf{R}_{\mathbf{F}}}$} & RMW & CMA & \multicolumn{1}{c}{ FMS } \\
\hline SMB & 1,000 & - & - & - & - & - \\
HML & $-0,186^{*}$ & 1,000 & - & - & - & - \\
$\mathbf{R}_{\mathbf{M}}-\mathbf{R}_{\mathbf{F}}$ & $-0,241^{* *}$ & $0,357^{* * *}$ & 1,000 & - & - & - \\
RMW & $-0,005$ & $-0,186^{*}$ & $-0,290^{* * *}$ & 1,000 & - & - \\
CMA & 0,068 & $-0,472^{* * *}$ & $-0,547^{* * *}$ & 0,107 & 1,000 & - \\
FMS & 0,036 & 0,135 & $0,369^{* * *}$ & $-0,230^{* *}$ & $-0,310^{* * *}$ & 1,000 \\
\hline
\end{tabular}

Fonte: elaborado pelo autor. $* * *$ Significativo a 0,01 . ** Significativo a 0,05 . ** Significativo a 0,10 .

Ainda ocorreram correlações significativas entre o fator de risco tamanho com o bookto-market $(-0,186)$ em sentido contrário; entre o book-to-market e o investimento $(-0,472)$. Além disso, o fator crescimento teve correlação significativa com a rentabilidade $(-0,230)$ e com o investimento $(-0,310)$, indicando que esses fatores explicam partes comuns das variações dos retornos, porém os valores das correlações não são altos. Já na amostra de FF 
(2015), os resultados foram um pouco similares para o tamanho, que foi negativamente correlacionado com book-to-market, rentabilidade e investimento; para a correlação entre investimento e rentabilidade também foi positiva; e para o fator prêmio de mercado, que foi negativamente relacionado com rentabilidade e investimento. Porém, foi diferente em relação ao fator prêmio de mercado, que na amostra de FF (2015) a correlação foi negativa com o book-to-market. Além disso, o fato da maioria das correlações ser abaixo de 0,400 pode indicar que os fatores explicam partes diferentes das variações dos retornos dos ativos, não sendo também identificada, redundância de nenhum fator de risco.

A análise foi realizada primeiramente com a construção de 16 carteiras de investimentos, onde a média de ações quando foram distribuídas variou de 5 a 16 ações. No Painel A da Tabela 3, constam as carteiras distribuídas por Tamanho-Crescimento, onde observa-se padrões em relação ao crescimento nos grupos Small e 2 de maneira crescente com os retornos; e nos grupos 3 e Big da classificação por tamanho uma tendência decrescente. No grupo Small, com exceção de Slow, o retorno passa de 0,018 para 0,028; no grupo 2, com exceção do grupo Fast de crescimento, o retorno em excesso passa de 0,007 para 0,027 . No grupo 3 , passa de 0,020 para 0,011 , com uma diferença de retorno de 0,009 ; já no grupo Big, passa de 0,020 para 0,006, com uma diferença de retorno de 0,014. Em relação ao tamanho, foram identificados padrões nos quatro grupos. No Slow, 3 e Fast, o retorno é crescente, passando de 0,029 para 0,020, no grupo Slow; 0,028 para 0,009, no grupo 3; e 0,028 a 0,006 no grupo Fast. Por sua vez no grupo 2, houve uma tendência no sentido inverso, de aumento dos retornos, passando de 0,018 para 0,022 , com uma diferença de 0,004 de retorno.

No Painel B da Tabela 3, nas carteiras formadas por Book-to-Market-Crescimento evidencia-se a presença de padrões em relação ao fator crescimento. Com exceção dos grupos Slow, os retornos em excesso do grupo Low passam de 0,034 para 0,010; do grupo 2, de 0,026 para 0,004 ; no grupo 3 de 0,014 para 0,006; todos indicando um movimento decrescente entre retornos em excesso e o fator de risco. Porém, no grupo High, os retornos em excesso crescem à medida que aumenta o fator de risco, passando de 0,010 para 0,029. Em relação ao efeito book-to-market, nos grupos Slow, 3 e Fast, há uma tendência de aumento dos retornos em excesso, passando e 0,007 a 0,031 no grupo Slow; de 0,012 a 0,026 no grupo 3 e 0,010 a 0,029 no grupo Fast. Por outro lado, o grupo 2, houve uma diminuição dos retornos em excesso, passando de 0,034 para 0,010 . 


\section{Tabela 3 - Retornos em excesso dos 16 portfólios formados pelo Tamanho e Crescimento; Book-to-Market e Crescimento; Rentabilidade e Crescimento; Investimento e Crescimento, ponderados pelo Valor de Mercado de julho de 2008 a junho de 2015, considerando 84 meses}

A alocação das carteiras foi realizada no começo de cada mês de julho do ano correspondente. A variável tamanho (SMB) foi construída pela mediana do valor de mercado das ações, considerando os dados do trimestre. A variável book-to-market (HML) foi construída pela divisão entre o valor contábil de ações ordinárias e o valor de mercado da empresa ao final do ano anterior. A variável rentabilidade (RMW) foi construída pela divisão entre a receita menos o CMV, despesas com juros e vendas, despesas gerais e despesas administrativas no ano anterior, e o patrimônio líquido. A variável investimento (CMA) foi construída a partir da divisão dos ativos totais no último ano e ativos totais no ano imediatamente anterior. A variável crescimento (FMS) foi construída pela divisão entre o crescimento da receita bruta de vendas da empresa e o crescimento do produto interno bruto no ano anterior, descontada a inflação do período. Após a construção das variáveis, as ações foram dispostas em ordem crescente e divididas em percentis de $25 \%$ cada um. Neste caso, os retornos das carteiras são ponderados pelo valor de mercado, sendo feita a média ponderada entre as ações.

\begin{tabular}{|c|c|c|c|c|c|c|c|c|c|}
\hline \multicolumn{5}{|c|}{ Painel A: Carteiras Tamanho-Crescimento } & \multicolumn{5}{|c|}{ Painel B: Carteiras Book-to-Market-Crescimento } \\
\hline & Slow & 2 & 3 & Fast & & Slow & 2 & 3 & Fast \\
\hline Small & 0,029 & 0,018 & 0,028 & 0,028 & Low & 0,007 & 0,034 & 0,012 & 0,010 \\
\hline 2 & 0,007 & 0,019 & 0,024 & 0,011 & 2 & 0,019 & 0,026 & 0,016 & 0,004 \\
\hline 3 & 0,020 & 0,030 & 0,019 & 0,011 & 3 & 0,013 & 0,014 & 0,011 & 0,006 \\
\hline Big & 0,020 & 0,022 & 0,009 & 0,006 & High & 0,031 & 0,010 & 0,026 & 0,029 \\
\hline \multicolumn{5}{|c|}{ Painel C: Carteiras Rentabilidade-Crescimento } & \multicolumn{5}{|c|}{ Painel D: Carteiras Investimento-Crescimento } \\
\hline & Slow & 2 & 3 & Fast & & Slow & 2 & 3 & Fast \\
\hline Weak & 0,021 & 0,010 & 0,040 & 0,013 & Conservative & 0,027 & 0,029 & 0,028 & 0,009 \\
\hline 2 & 0,017 & 0,019 & 0,010 & 0,004 & 2 & 0,026 & 0,030 & 0,027 & 0,022 \\
\hline 3 & 0,019 & 0,024 & 0,011 & 0,005 & 3 & 0,026 & 0,017 & 0,008 & 0,009 \\
\hline Robust & 0,002 & 0,028 & 0,008 & 0,013 & Agressive & $-0,007$ & 0,012 & 0,006 & 0,009 \\
\hline
\end{tabular}

Fonte: elaborado pelo autor.

Já no Painel C da Tabela 3, observam-se as carteiras formadas por RentabilidadeCrescimento. O padrão da variável crescimento é verificado nas carteiras dos grupos 2, 3 e Robust da classificação por rentabilidade. Há uma tendência de queda à medida que as carteiras passam de Slow para Fast, onde no grupo 2, há uma diferença de retorno de 0,013 e no grupo 3 uma diferença de 0,014 entre os grupos extremos. Já, no grupo Robust, há uma tendência de aumento dos retornos ao aumentaram a relação entre o crescimento das receitas e o crescimento no PIB, passando de 0,002 para 0,013 os retornos em excesso. No que diz respeito à rentabilidade, nos grupos Slow, 2 e Fast da classificação por crescimento, verificase uma tendência de alta nos retornos em excesso, ou seja, ao se tornarem mais robustas, as carteiras aumentam seus retornos, passando de 0,017 para 0,022 no grupo Slow; 0,010 para 0,028, no grupo 2; e 0,004 para 0,013, no grupo Fast. No grupo 3, verifica-se uma tendência de queda, onde os retornos passam de 0,040 para 0,008, com uma diferença de 0,032.

E no Painel D da Tabela 3, tem-se as carteiras formadas por InvestimentoCrescimento. Em relação ao crescimento, observam-se padrões nos quatro grupos de carteiras. Em três, à medida que vão se tornando Fast, seus retornos diminuem, passando de 
0,029 para 0,009, no grupo Consevative; 0,030 para 0,022, no grupo 2; 0,026 para 0,009, no grupo 3. Por outro lado, no grupo Agressive, os retornos em excesso apresentaram padrão contrário, aumentando com o aumento da relação entre o crescimento da receita e crescimento do PIB, passando de $-0,007$ para 0,009, com uma diferença de retorno de 0,016. Já a identificação do efeito investimento se verifica nos grupos Slow, 2 e 3 de crescimento, passando de 0,027 para -0,007, no grupo Slow; 0,029 para 0,012, no grupo 2; de 0,028 para 0,006, no grupo 3. Nos três grupos, a relação entre os retornos em excesso e o investimento é decrescente.

Observa-se então, relações, em sua maioria, decrescentes entre o tamanho e os retornos em excesso; crescentes entre os retornos e book-to-market; crescentes entre rentabilidade e os retornos; decrescentes entre investimento e os retornos. Porém com o fator crescimento houveram vários grupos com padrões de comportamento crescente $\mathrm{e}$ decrescentes em relação aos retornos e fatores de risco, sendo necessárias novas análises. Sendo assim, observando os trabalhos já desenvolvidos acerca das relações entre os fatores e os retornos, em relação ao efeito tamanho, para FF (2015), o retorno em excesso também é decrescente em relação ao tamanho da empresa, indicando que as carteiras menores têm um retorno superior aos das maiores.

Sobre o efeito valor, para FF (2015), à medida que aumenta a relação book-to-market, o retorno médio das carteiras também cresce, igualmente aos resultados dessa amostra. Sobre a rentabilidade, para FF (2015), ela se relaciona com os retornos de forma crescente, onde, à medida que as empresas são mais rentáveis, seus retornos aumentam. Já em relação ao efeito investimento, para FF (2015), o fator investimento está relacionado com retornos em excesso menores, igualmente à amostra dessa pesquisa. Como a variável macroeconômica ainda não foi analisada por outros autores, não é possível realizar a comparação com outros estudos.

\subsubsection{Coeficientes e poder explicativo dos modelos}

\subsubsection{Modelos de cinco fatores}

$\mathrm{Na}$ Tabela 4, tem-se os coeficientes das regressões no modelo de cinco fatores de FF. Os coeficientes significativos da constante foram 23, indicando que ainda há parte das variações dos retornos não explicadas pelo modelo. O prêmio de mercado foi significativo nas 32 carteiras, confirmando que ele tem forte poder preditivo sobre os retornos em excesso. Por sua vez, o fator tamanho teve 19 coeficientes significativos, seguido pela rentabilidade com 17, investimento com 16 e book-to-market com 14, indicando que em geral, os fatores 
explicativos conseguem explicar parte das variações dos retornos na maioria das carteiras. $\mathrm{O}$ book-to-market foi o fator menos significativo nas carteiras, corroborando pelo fato de ter correlação significativa com todos os fatores de risco.

\section{Tabela 4 - Regressões com dados em Séries Temporais das 32 Carteiras construídas com fatores RM-RF, SMB, HML, RMW e CMA}

Esta tabela apresenta os coeficientes das variáveis explicativas dos modelos e os $\mathrm{R}^{2}$ ajustados das 32 carteiras de ações. As variáveis estudadas foram tamanho (SMB), book-to-market (HML), prêmio de mercado $\left(\mathrm{R}_{\mathrm{M}}-\mathrm{R}_{\mathrm{F}}\right)$, rentabilidade (RMW), investimento (CMA) e crescimento (FMS). Nesta tabela, o modelo com fatores $R_{M}-R_{F}$, SMB, HML, RMW e CMA. As definições das variáveis características das empresas podem ser visualizadas na seção 2.2 .

\begin{tabular}{|c|c|c|c|c|c|c|c|}
\hline Carteiras & Constante & SMB & HML & $\mathbf{R}_{\mathbf{M}}-\mathbf{R}_{\mathbf{F}}$ & RMW & СМА & $\begin{array}{c}\mathbf{R}^{2} \\
\text { Ajust. }\end{array}$ \\
\hline C1 & $0,017 *$ & $0,058 * * *$ & $0,055^{* *}$ & $0,463 * * *$ & 0,014 & $0,063 * * *$ & 0,159 \\
\hline $\mathrm{C} 2$ & $0,020 * * *$ & $0,054 * * *$ & 0,01 & $0,943 * * *$ & 0,003 & $-0,009$ & 0,466 \\
\hline C3 & $0,014 * *$ & $0,050 * * *$ & $0,066 * * *$ & $0,557 * * *$ & $-0,060 * * *$ & 0,013 & $\mathbf{0 , 5 5 3}$ \\
\hline $\mathrm{C4}$ & $0,014^{*}$ & $0,098 * * *$ & $0,079 * * *$ & $0,691 * * *$ & $-0,050 * * *$ & $-0,023$ & 0,608 \\
\hline C5 & $0,034 * * *$ & $0,080 * * *$ & 0,004 & $0,726 * * *$ & 0,007 & 0,028 & 0,256 \\
\hline C6 & 0,002 & $0,038 * * *$ & 0,005 & $0,932 * * *$ & 0,006 & $-0,005$ & 0,500 \\
\hline C7 & 0,01 & $0,075 * * *$ & 0,003 & $0,976 * * *$ & $-0,043^{*}$ & $0,087 * * *$ & $\mathbf{0 , 3 7 7}$ \\
\hline C8 & $0,020 * *$ & $0,074 * * *$ & $-0,033$ & $0,711 * * *$ & $-0,026$ & $-0,067 * * *$ & 0,440 \\
\hline C9 & 0,006 & 0,021 & $0,093 * *$ & $0,836 * * *$ & $0,100 * * *$ & 0,04 & 0,311 \\
\hline C10 & 0,013 & $-0,012$ & $0,068 * * *$ & $0,859 * * *$ & 0,037 & $-0,012$ & 0,367 \\
\hline C11 & $0,024 * *$ & $-0,007$ & $0,092 * * *$ & $0,805 * * *$ & $-0,064 * * *$ & $0,064 * * *$ & 0,485 \\
\hline C12 & $0,022 * *$ & $-0,033 *$ & 0,018 & $0,678 * * *$ & $-0,082 * * *$ & 0,004 & 0,453 \\
\hline C13 & $0,020 * * *$ & 0,003 & $-0,008$ & $0,523 * * *$ & 0,018 & $0,029^{*}$ & 0,122 \\
\hline C14 & $0,011 *$ & 0,000 & 0,007 & $0,816 * * *$ & $-0,015$ & 0,005 & $\mathbf{0 , 5 0 7}$ \\
\hline C15 & 0,008 & $-0,026$ & $-0,025$ & $0,690 * * *$ & $-0,059 * * *$ & 0,021 & 0,365 \\
\hline C16 & 0,015 & $0,044 * *$ & 0,034 & $0,891 * * *$ & $-0,027$ & 0,001 & 0,408 \\
\hline C17 & 0,006 & $0,047 * * *$ & $0,050 * * *$ & $0,570 * * *$ & 0,013 & $0,029 * *$ & 0,381 \\
\hline C18 & $0,024 * *$ & $0,072 * * *$ & $0,094 * * *$ & $0,572 * *$ & $0,063 * *$ & $-0,038$ & 0,341 \\
\hline C19 & $0,016 * *$ & $0,080 * * *$ & $0,072 * * *$ & $0,609 * * *$ & $-0,008$ & $0,081 * * *$ & 0,444 \\
\hline $\mathrm{C20}$ & $0,017 * *$ & $0,065 * * *$ & $0,088 * * *$ & $0,610 * * *$ & $-0,054 * * *$ & $0,051 * *$ & 0,457 \\
\hline C21 & $0,015^{*}$ & $0,044 * * *$ & 0,001 & $0,774 * * *$ & 0,006 & $0,083 * * *$ & 0,236 \\
\hline $\mathrm{C} 22$ & $0,026 * * *$ & $0,044 * * *$ & $-0,006$ & $0,445 * * *$ & $0,051 * * *$ & $-0,039 * *$ & 0,282 \\
\hline $\mathrm{C} 23$ & 0,014 & $0,036^{*}$ & $-0,014$ & $0,960 * * *$ & $-0,054 * *$ & $0,098 * * *$ & $\mathbf{0 , 3 2 9}$ \\
\hline $\mathrm{C} 24$ & 0,008 & $0,053 * * *$ & 0,003 & $0,522 * * *$ & $-0,055^{* *}$ & $-0,006$ & 0,199 \\
\hline $\mathrm{C} 25$ & $0,012^{*}$ & 0,007 & $0,062 * * *$ & $0,851 * * *$ & 0,011 & $0,053 * * *$ & 0,430 \\
\hline $\mathrm{C} 26$ & $-0,021 * * *$ & $-0,053 * * *$ & $0,050 * * *$ & $0,313 * *$ & $0,051 * * *$ & $-0,021$ & 0,526 \\
\hline C27 & $0,019 * * *$ & $-0,019$ & $0,052 * * *$ & $0,732 * * *$ & $-0,031 * *$ & $0,054 * * *$ & 0,456 \\
\hline $\mathrm{C} 28$ & $0,027 * *$ & $-0,006$ & $0,063 * *$ & $0,957 * * *$ & $-0,056^{* *}$ & $-0,043 *$ & 0,544 \\
\hline C29 & $0,025 * * *$ & 0,016 & $-0,004$ & $0,823 * * *$ & $-0,012$ & $0,062 * * *$ & 0,384 \\
\hline C30 & $0,023 * * *$ & 0,002 & 0,008 & $0,525 * * *$ & $0,031 * *$ & 0,02 & 0,182 \\
\hline C31 & $0,031 * * *$ & $-0,008$ & $-0,007$ & $0,451 * * *$ & $-0,01$ & $0,066 * * *$ & 0,197 \\
\hline C32 & $0,013 * *$ & $-0,018$ & $-0,006$ & $0,544 * * *$ & $-0,035^{* *}$ & $-0,021$ & 0,445 \\
\hline
\end{tabular}

Fonte: elaborado pelo autor. ${ }^{* * *}$ Significativo a $0,01 . * *$ Significativo a $0,05 . *$ Significativo a 0,10 .

Os coeficientes dos fatores indicam relações dos retornos em excesso negativas com o tamanho; positiva com o book-to-market; positiva com a rentabilidade e negativa com o investimento; sendo elas semelhantes àquelas encontradas nos painéis da Tabela 3 e nos REAd | Porto Alegre - Vol. 24 - No 3 - Setembro / Dezembro 2018 - p. 269-293 
estudos de FF (2015). Neste modelo pode-se verificar também que em apenas uma carteira (C20) todos os coeficientes foram significativos. Além disso, as carteiras do tipo Small tiveram 16 coeficientes significativos, enquanto as do tipo Big, 3 coeficientes; todas as carteiras significativas em relação ao fator book-to-market foram do tipo High; as carteiras do tipo Weak tiveram 12 coeficientes significativos, enquanto as do tipo Robust, 5; e as carteiras do tipo Conservative tiveram 12 coeficientes significativos e as do tipo Agressive tiveram apenas 5; indicando assim que o modelo foi capaz de capturar melhor as variações das carteiras do tipo Small, High, Weak e Conservative. Já o $\mathrm{R}^{2}$ variou de 0,122 a 0,608, indicando ainda que boa parte das variações dos retornos ainda não foram explicadas pelo menos, o que é corroborado pela quantidade de coeficientes da constante significativos. Tais resultados ainda ficaram aquém daqueles encontrados por FF (2015) nos EUA em relação ao $\mathrm{R}^{2}$ das carteiras, que variaram de 0,85 a 0,93 .

Foi realizado então um modelo de cinco fatores com a substituição da variável investimento, pela variável macroeconômica crescimento. $\mathrm{Na}$ Tabela 5, tem-se os coeficientes das regressões das 32 carteiras utilizadas para análise com este modelo. Este foi o modelo em que a constante obteve menos coeficientes significativos (22), já o prêmio de mercado foi significativo em 31 carteiras.

Com relação ao tamanho verifica-se, na Tabela 5, que obteve 19 coeficientes significativos, como no modelo de cinco fatores, indicando que o tamanho explica partes diferentes das variações dos retornos, em relação à introdução do crescimento. O book-tomarket teve um aumento para 16 coeficientes significativos em relação ao modelo de cinco fatores, indicando que com a saída do investimento do modelo, parte das variações dos retornos passa a ser explicada pelo book-to-market, isso pode ser corroborado pela correlação significativa entre as variáveis $(-0,472)$. O fator rentabilidade aumentou o número de coeficientes significativos em relação ao modelo de cinco fatores original, onde passou de 17 para 19 coeficientes significativos. Já o fator crescimento, que foi introduzido no lugar do investimento, foi significativo em 18 carteiras, com um número superior ao investimento no modelo anterior (16). Sobre a variável crescimento, observa-se pelas regressões que a relação entre os retornos em excesso das carteiras e o fator de risco é positiva, ou seja, à medida que as empresas aumentam a relação entre crescimento da receita e o crescimento do PIB de mercado, há uma tendência de aumentar os seus retornos em excesso. Já sobre os coeficientes de determinação, observa-se uma leve tendência de queda em relação ao modelo anterior, no geral, porém com uma maior amplitude, onde o $\mathrm{R}^{2}$ variou de 0,047 a 0,711 . Ainda assim, há 
necessidade de busca por mais variáveis explicativas visto que boa parte da variação dos retornos ainda não foi explicada.

\section{Tabela 5 - Regressões com dados em Séries Temporais das 32 Carteiras construídas com fatores $R_{M}-R_{F}$, SMB, HML, RMW e FMS}

Esta tabela apresenta os coeficientes das variáveis explicativas dos modelos e os $\mathrm{R}^{2}$ ajustados das 32 carteiras de ações. As variáveis estudadas foram tamanho (SMB), book-to-market (HML), prêmio de mercado $\left(\mathrm{R}_{\mathrm{M}}-\mathrm{R}_{\mathrm{F}}\right)$, rentabilidade (RMW), investimento (CMA) e crescimento (FMS). Nesta tabela, o modelo com fatores $R_{M}-R_{F}$, SMB, HML, RMW e FMS. As definições das variáveis podem ser visualizadas na seção 2.2.

\begin{tabular}{|c|c|c|c|c|c|c|c|}
\hline Carteiras & Constante & SMB & HML & $\mathbf{R}_{\mathbf{M}}-\mathbf{R}_{\mathbf{F}}$ & RMW & FMS & $\begin{array}{c}\mathbf{R}^{2} \\
\text { Ajust. }\end{array}$ \\
\hline C1 & $0,023 * *$ & $0,046^{* *}$ & 0,031 & 0,104 & 0,013 & $0,043 * *$ & 0,119 \\
\hline $\mathrm{C} 2$ & $0,020 * * *$ & $0,050 * * *$ & 0,013 & $0,862 * * *$ & 0,009 & $0,042 * * *$ & 0,509 \\
\hline C3 & $0,015 * *$ & $0,045 * * *$ & $0,060 * * *$ & $0,442 * * *$ & $-0,059 * * *$ & $0,023 *$ & 0,565 \\
\hline $\mathrm{C4}$ & $0,013^{*}$ & $0,091 * * *$ & $0,087 * * *$ & $0,562 * * *$ & $-0,037 * *$ & $0,081 * * *$ & 0,711 \\
\hline C5 & $0,036 * * *$ & $0,073 * * *$ & $-0,007$ & $0,538 * * *$ & 0,008 & 0,029 & 0,261 \\
\hline C6 & 0,002 & $0,037 * * *$ & 0,007 & $0,911 * * *$ & 0,009 & 0,015 & 0,506 \\
\hline C7 & 0,017 & $0,069 * * *$ & $-0,036$ & $0,759 * * *$ & $-0,060 * *$ & $-0,04$ & 0,277 \\
\hline C8 & $0,016^{*}$ & $0,074 * * *$ & $-0,008$ & $0,783 * * *$ & $-0,01$ & $0,070 * * *$ & 0,461 \\
\hline C9 & 0,007 & 0,006 & $0,096 * * *$ & $0,685 * * *$ & $0,094 * *$ & $0,060 *$ & $\mathbf{0 , 3 3 7}$ \\
\hline C10 & 0,013 & $-0,018$ & $0,072 * * *$ & $0,731 * * *$ & $0,047 * *$ & $0,066^{* * *}$ & 0,428 \\
\hline C11 & $0,032 * * *$ & $-0,019$ & $0,062 * * *$ & $0,467 * * *$ & $-0,069 * * *$ & 0,027 & 0,442 \\
\hline C12 & $0,023 * * *$ & $-0,036 * *$ & 0,017 & $0,609 * * *$ & $-0,080 * * *$ & 0,02 & 0,461 \\
\hline C13 & $0,022 * * *$ & $-0,003$ & $-0,019$ & $0,359 * * *$ & 0,017 & 0,02 & 0,107 \\
\hline C14 & $0,012 * *$ & $-0,001$ & 0,005 & $0,806^{* * *}$ & $-0,016$ & $-0,004$ & $\mathbf{0 , 5 0 7}$ \\
\hline C15 & 0,008 & $-0,035^{* *}$ & $-0,021$ & $0,590 * * *$ & $-0,062 * * *$ & $0,031 *$ & 0,382 \\
\hline C16 & $0,015^{*}$ & $0,038 * *$ & $0,033^{*}$ & $0,758 * * *$ & $-0,021$ & $0,047 * *$ & 0,453 \\
\hline C17 & 0,008 & $0,045 * * *$ & $0,039 * * *$ & $0,500 * * *$ & 0,008 & $-0,015$ & 0,358 \\
\hline C18 & $0,020 *$ & $0,084 * * *$ & $0,109 * * *$ & $0,899 * * *$ & $0,058 * *$ & $-0,067 * * *$ & 0,384 \\
\hline C19 & $0,022 * * *$ & $0,075 * * *$ & $0,041 * *$ & $0,413 * * *$ & $-0,023$ & $-0,044 * * *$ & 0,326 \\
\hline $\mathrm{C20}$ & $0,019 * *$ & $0,068 * * *$ & $0,068 * * *$ & $0,594 * * *$ & $-0,069 * * *$ & $-0,069 * * *$ & 0,522 \\
\hline C21 & $0,021 * *$ & $0,041 * *$ & $-0,031$ & $0,582 * * *$ & $-0,009$ & $-0,049 * *$ & 0,140 \\
\hline $\mathrm{C} 22$ & $0,022 * * *$ & $0,049 * * *$ & 0,009 & $0,601 * * *$ & $0,056^{* * *}$ & $-0,005$ & 0,240 \\
\hline $\mathrm{C} 23$ & 0,019 & 0,027 & $-0,057 * *$ & $0,486^{* *}$ & $-0,073 * * *$ & 0,012 & $\mathbf{0 , 2 0 0}$ \\
\hline $\mathrm{C} 24$ & 0,008 & $0,064 * * *$ & $-0,01$ & $0,629 * * *$ & $-0,055^{* *}$ & $-0,064 * * *$ & 0,300 \\
\hline $\mathrm{C} 25$ & 0,015 & 0,006 & $0,041 * *$ & $0,745 * * *$ & 0,001 & $-0,034 * *$ & 0,394 \\
\hline $\mathrm{C} 26$ & $-0,020 * * *$ & $-0,047 * * *$ & $0,053 * * *$ & $0,364 * * *$ & $0,054 * * *$ & $-0,012$ & 0,517 \\
\hline C27 & $0,023 * * *$ & $-0,021$ & $0,032 *$ & $0,612 * * *$ & $-0,042 * *$ & $-0,033 * *$ & 0,415 \\
\hline $\mathrm{C} 28$ & $0,022 * *$ & 0,006 & $0,079 * * *$ & $1,304 * * *$ & $-0,060 * * *$ & $-0,068 * * *$ & 0,578 \\
\hline C29 & $0,029 * * *$ & 0,015 & $-0,027^{*}$ & $0,725 * * *$ & $-0,026^{*}$ & $-0,053 * * *$ & 0,366 \\
\hline C30 & $0,025 * * *$ & $-0,001$ & 0 & $0,446 * * *$ & $0,029 * *$ & 0,001 & 0,165 \\
\hline C31 & $0,032 * * *$ & $-0,009$ & $-0,017$ & $0,358 * *$ & $-0,017$ & $-0,008$ & 0,047 \\
\hline C32 & $0,011 *$ & $-0,014$ & 0,002 & $0,648 * * *$ & $-0,034 * *$ & $-0,008$ & $\mathbf{0 , 4 3 3}$ \\
\hline
\end{tabular}

Fonte: elaborado pelo autor. ${ }^{* * *}$ Significativo a $0,01 .{ }^{* *}$ Significativo a $0,05 . *$ Significativo a 0,10 .

Por sua vez, na Tabela 6, tem-se os coeficientes das regressões das 32 carteiras no modelo de cinco Fatores de FF, com variáveis CMA e FMS. Em relação a constante, ela foi 
significativa em 24 carteiras, ou seja, dentre os modelos de cinco fatores, este também foi um dos que menos conseguiram capturar as variações dos retornos. Já a variável prêmio de mercado, neste modelo, foi significativa em um total de 31 carteiras.

\section{Tabela 6 - Regressões com dados em Séries Temporais das 32 Carteiras construídas com fatores RM-RF, SMB, HML, CMA e FMS}

Esta tabela apresenta os coeficientes das variáveis explicativas dos modelos e os $\mathrm{R}^{2}$ ajustados das 32 carteiras de ações. As variáveis estudadas foram tamanho (SMB), book-to-market (HML), prêmio de mercado $\left(\mathrm{R}_{\mathrm{M}}-\mathrm{R}_{\mathrm{F}}\right)$, rentabilidade (RMW), investimento (CMA) e crescimento (FMS). Nesta tabela, o modelo com fatores $R_{M}-R_{F}$, SMB, HML, CMA e FMS. As definições das variáveis podem ser visualizadas na seção 2.2.

\begin{tabular}{|c|c|c|c|c|c|c|c|}
\hline Carteiras & Constante & SMB & HML & $\mathbf{R}_{\mathbf{M}}-\mathbf{R}_{\mathbf{F}}$ & СМА & FMS & $\begin{array}{c}\mathbf{R}^{2} \\
\text { Ajust. }\end{array}$ \\
\hline $\mathrm{C1}$ & $0,016^{*}$ & $0,052 * * *$ & $0,054 * * *$ & $0,31 *$ & $0,068 * * *$ & $0,05 * * *$ & 0,224 \\
\hline $\mathrm{C} 2$ & $0,020 * * *$ & $0,049 * * *$ & 0,011 & $0,837 * * *$ & $-0,003$ & $0,041 * *$ & $\mathbf{0 , 5 0 7}$ \\
\hline C3 & $0,015 * *$ & $0,051 * * *$ & $0,076^{* * *}$ & $0,619 * * *$ & 0,026 & $0,034 * *$ & 0,487 \\
\hline $\mathrm{C} 4$ & $0,015 * *$ & $0,093 * * *$ & $0,089 * * *$ & $0,604 * * *$ & $-0,005$ & $0,085 * * *$ & 0,691 \\
\hline C5 & $0,033 * * *$ & $0,076 * * *$ & 0,004 & $0,632 * * *$ & 0,032 & $0,032 *$ & 0,281 \\
\hline C6 & 0,002 & $0,036 * * *$ & 0,005 & $0,885 * * *$ & $-0,004$ & 0,014 & 0,505 \\
\hline C7 & 0,011 & $0,079 * * *$ & 0,009 & $1,111 * * *$ & $0,091 * * *$ & $-0,02$ & 0,349 \\
\hline C8 & $0,021 * *$ & $0,070 * * *$ & $-0,027$ & $0,617 * * *$ & $-0,055^{* *}$ & $0,065 * * *$ & 0,504 \\
\hline C9 & 0,008 & 0,017 & $0,114 * * *$ & $0,746^{* * *}$ & 0,027 & $0,063 *$ & 0,256 \\
\hline $\mathrm{C10}$ & 0,012 & $-0,022$ & $0,064 * *$ & $0,630 * * *$ & $-0,009$ & $0,059 * *$ & 0,399 \\
\hline C11 & $0,026^{* *}$ & $-0,003$ & $0,100 * * *$ & $0,859 * * *$ & $0,085 * * *$ & $0,050 * *$ & 0,458 \\
\hline C12 & $0,025 * * *$ & $-0,029$ & 0,032 & $0,795 * * *$ & 0,019 & 0,033 & $\mathbf{0 , 3 5 3}$ \\
\hline C13 & $0,019 * * *$ & $-0,001$ & $-0,01$ & $0,431 * * *$ & $0,030 *$ & 0,021 & $\mathbf{0 , 1 3 0}$ \\
\hline C14 & $0,012^{*}$ & 0,001 & 0,009 & $0,856^{* * *}$ & 0,007 & $-0,002$ & 0,499 \\
\hline C15 & 0,009 & $-0,030^{*}$ & $-0,022$ & $0,732 * * *$ & 0,029 & 0,029 & 0,299 \\
\hline C16 & $0,015^{*}$ & $0,041 * *$ & $0,040 *$ & $0,831 * * *$ & 0,012 & $0,052 * * *$ & 0,447 \\
\hline C17 & 0,006 & $0,047 * * *$ & $0,048 * * *$ & $0,571 * * *$ & $0,025^{*}$ & $-0,013$ & 0,382 \\
\hline C18 & $0,022 *$ & $0,075 * * *$ & $0,082 * * *$ & $0,619 * * *$ & $-0,057 * *$ & $-0,081 * * *$ & 0,379 \\
\hline C19 & $0,016 * *$ & $0,084 * * *$ & $0,072 * * *$ & $0,707 * * *$ & $0,078 * * *$ & $-0,032 * *$ & 0,476 \\
\hline $\mathrm{C20}$ & $0,019 * *$ & $0,075 * * *$ & $0,095 * * *$ & $0,848 * * *$ & $0,048 * *$ & $-0,054 * * *$ & 0,464 \\
\hline C21 & $0,015^{*}$ & $0,048 * * *$ & $-0,002$ & $0,852 * * *$ & $0,077 * * *$ & $-0,039 * *$ & 0,277 \\
\hline $\mathrm{C22}$ & $0,025 * * *$ & $0,042 * * *$ & $-0,013$ & $0,364 * *$ & $-0,048 * *$ & $-0,014$ & 0,207 \\
\hline $\mathrm{C} 23$ & 0,015 & $0,036^{*}$ & $-0,002$ & $1,080 * * *$ & $0,116 * * *$ & 0,033 & $\mathbf{0 , 3 0 3}$ \\
\hline $\mathrm{C} 24$ & 0,009 & $0,067 * * *$ & $-0,012$ & $0,729 * * *$ & 0,015 & $-0,065 * * *$ & 0,231 \\
\hline $\mathrm{C25}$ & $0,012^{*}$ & 0,01 & $0,059 * * *$ & $0,894 * * *$ & $0,047 * * *$ & $-0,029 *$ & 0,451 \\
\hline $\mathrm{C} 26$ & $-0,020 * * *$ & $-0,052 * * *$ & $0,051 * * *$ & 0,243 & $-0,026$ & $-0,005$ & 0,438 \\
\hline C27 & $0,020 * * *$ & $-0,014$ & $0,056^{* * *}$ & $0,857 * * *$ & $0,055 * * *$ & $-0,021$ & 0,442 \\
\hline $\mathrm{C} 28$ & $0,029 * * *$ & 0,006 & $0,069 * * *$ & $1,248 * * *$ & $-0,045^{*}$ & $-0,066 * * *$ & $\mathbf{0 , 5 5 9}$ \\
\hline C29 & $0,025 * * *$ & $0,022 *$ & $-0,003$ & $0,955 * * *$ & $0,058 * * *$ & $-0,043 * * *$ & 0,457 \\
\hline C30 & $0,022 * * *$ & $-0,001$ & 0,003 & $0,452 * * *$ & 0,016 & 0,000 & 0,132 \\
\hline C31 & $0,031 * * *$ & $-0,003$ & $-0,01$ & $0,507 * * *$ & $0,070 * * *$ & $-0,016$ & 0,203 \\
\hline C32 & $0,014 * *$ & $-0,014$ & $-0,001$ & $0,642 * * *$ & $-0,018$ & $-0,006$ & 0,400 \\
\hline
\end{tabular}

Fonte: elaborado pelo autor. $* * *$ Significativo a $0,01 . * *$ Significativo a $0,05 . *$ Significativo a $0,10$. 
Além disso, este modelo confirma a constatação existente no modelo anterior que a rentabilidade capta as variações dos retornos melhor do que o investimento, visto que os coeficientes significativos deste fator foram vistos em 17 carteiras, enquanto no caso da rentabilidade no modelo anterior, foram em 19 carteiras. Por sua vez, a variável crescimento foi significativa em 18 carteiras, mesma quantidade do modelo de cinco fatores com a rentabilidade. Tal manutenção pode ser corroborada pela correlação entre o crescimento e tais variáveis, visto que ela é significativa e quase na mesma intensidade. Em relação aos modelos anteriores de cinco fatores propostos, verifica-se que o $\mathrm{R}^{2}$ variou de 0,130 a 0,691 , indicando que a presença do investimento e crescimento também melhora o poder explicativos dos modelos.

\subsubsection{Modelo de seis fatores}

$\mathrm{Na}$ Tabela 7, tem-se os coeficientes das regressões das 32 carteiras utilizadas para análise no modelo de 5 Fatores de FF com variável crescimento (FMS). Novamente, o prêmio de mercado foi significativo nas 32 carteiras, já a constante em 24 delas, indicando que mesmo com a presença dos seis fatores, a constante permanece significativa na maioria das carteiras também. Em relação ao tamanho e ao book-to-market, eles foram significativos em 20 e 15 carteiras, respectivamente, confirmando que o tamanho não é afetado pela presença dos novos fatores de risco e que os novos fatores de risco podem captar as variações dos retornos antes capturados pelo book-to-market.

Além disso, ressalta-se a significância do fator de risco de crescimento, em 19 carteiras de investimentos, superior aos fatores rentabilidade (18) e investimento (17). Salienta-se então a importância da inclusão desse fator de risco nos modelos multifatoriais, visto que ele possui baixa correlação com os outros fatores de risco, indicando que ele pode captar variações dos retornos não captadas por esses fatores. Neste modelo também apenas duas carteiras tiveram todos os coeficientes significativos, elas foram as carteiras C18 e C20. No que diz respeito aos coeficientes de determinação, observa-se que neste modelo com seis fatores ele possui um aumento em relação aos anteriores, variando de 0,139 a 0,709. Apenas em cinco das 32 carteiras não houve um incremento do coeficiente de determinação do modelo quando incluídos os seis fatores de risco. Por sua vez, a carteira que obteve maior $\mathrm{R}^{2}$, o de 0,709, foi a carteira C4, classificada como Small-High-Weak-Agressive-Fast. 
Tabela 7 - Regressões com dados em Séries Temporais das 32 Carteiras construídas com fatores $R_{M-R}$, SMB, HML, RMW, CMA e FMS

Esta tabela apresenta os coeficientes das variáveis explicativas dos modelos e os $\mathrm{R}^{2}$ ajustados das 32 carteiras de ações. As variáveis estudadas foram tamanho (SMB), book-to-market (HML), prêmio de mercado $\left(\mathrm{R}_{\mathrm{M}}-\mathrm{R}_{\mathrm{F}}\right)$, rentabilidade (RMW), investimento (CMA) e crescimento (FMS). Nesta tabela, o modelo com fatores $R_{M}-R_{F}$, SMB, HML, RMW, CMA e FMS. As definições das variáveis podem ser visualizadas na seção 2.2.

\begin{tabular}{|c|c|c|c|c|c|c|c|c|}
\hline Carteiras & Constante & SMB & HML & $\mathbf{R}_{M}-R_{F}$ & RMW & CMA & FMS & $\mathbf{R}^{2}$ Ajust. \\
\hline C1 & $0,017 * *$ & $0,053 * * *$ & $0,058 * * *$ & $0,354 * *$ & 0,022 & $0,071 * * *$ & $0,053 * * *$ & 0,227 \\
\hline $\mathrm{C2}$ & $0,020 * * *$ & $0,050 * * *$ & 0,012 & $0,856^{* * *}$ & 0,009 & $-0,002$ & $0,042 * *$ & 0,502 \\
\hline C3 & $0,014 * *$ & $0,047 * * *$ & $0,067 * * *$ & $0,504 * * *$ & $-0,057 * * *$ & 0,018 & $0,026^{*}$ & 0,567 \\
\hline $\mathrm{C4}$ & $0,014 * *$ & $0,090 * * *$ & $0,083 * * *$ & $0,527 * * *$ & $-0,038 * *$ & $-0,01$ & $0,080 * * *$ & 0,709 \\
\hline C5 & $0,034 * * *$ & $0,076^{* * *}$ & 0,006 & $0,656^{* * *}$ & 0,012 & 0,034 & $0,034^{*}$ & 0,275 \\
\hline C6 & 0,002 & $0,037 * * *$ & 0,006 & $0,901 * * *$ & 0,008 & $-0,003$ & 0,015 & 0,500 \\
\hline C7 & 0,009 & $0,079 * * *$ & 0,001 & $1,023 * * *$ & $-0,047 * *$ & $0,083 * * *$ & $-0,028$ & 0,381 \\
\hline C8 & $0,020 * *$ & $0,068 * * *$ & $-0,03$ & $0,583 * * *$ & $-0,017$ & $-0,057 * * *$ & $0,063 * * *$ & 0,502 \\
\hline C9 & 0,006 & 0,014 & $0,103 * * *$ & $0,771 * * *$ & $0,096 * * *$ & 0,032 & $0,056^{*}$ & 0,336 \\
\hline C10 & 0,013 & $-0,019$ & $0,072 * * *$ & $0,725 * * *$ & $0,047^{*}$ & $-0,002$ & $0,065 * * *$ & 0,420 \\
\hline C11 & $0,024 * *$ & $-0,01$ & $0,091 * * *$ & $0,724 * * *$ & $-0,057 * * *$ & $0,073 * * *$ & $0,040 * *$ & 0,504 \\
\hline C12 & $0,022 * *$ & $-0,035^{* *}$ & 0,02 & $0,635 * * *$ & $-0,079 * * *$ & 0,007 & 0,021 & 0,455 \\
\hline C13 & $0,020 * * *$ & 0,000 & $-0,007$ & $0,474 * * *$ & 0,021 & $0,033 * *$ & 0,024 & 0,139 \\
\hline C14 & $0,011^{*}$ & 0,000 & 0,007 & $0,824 * * *$ & $-0,016$ & 0,005 & $-0,004$ & 0,501 \\
\hline C15 & 0,008 & $-0,032 *$ & $-0,019$ & $0,637 * * *$ & $-0,059 * * *$ & 0,017 & 0,029 & 0,379 \\
\hline C16 & $0,015^{*}$ & $0,039 * *$ & $0,037 *$ & $0,791 * * *$ & $-0,02$ & 0,009 & $0,049 * *$ & 0,447 \\
\hline C17 & 0,006 & $0,048 * * *$ & $0,050 * * *$ & $0,594 * * *$ & 0,011 & $0,027 *$ & $-0,012$ & 0,380 \\
\hline C18 & $0,024 * *$ & $0,079 * * *$ & $0,090 * * *$ & $0,724 * * *$ & $0,052 * *$ & $-0,050 *$ & $-0,074 * * *$ & 0,403 \\
\hline C19 & $0,016^{* *}$ & $0,083 * * *$ & $0,070 * * *$ & $0,679 * * *$ & $-0,014$ & $0,076^{* * *}$ & $-0,034 * *$ & 0,475 \\
\hline $\mathrm{C20}$ & $0,016^{* *}$ & $0,072 * * *$ & $0,083 * * *$ & $0,743 * * *$ & $-0,065 * * *$ & $0,040 * *$ & $-0,064 * * *$ & 0,545 \\
\hline C21 & $0,015^{*}$ & $0,048 * * *$ & $-0,001$ & $0,853 * * *$ & 0,001 & $0,077 * * *$ & $-0,038 * *$ & 0,268 \\
\hline $\mathrm{C} 22$ & $0,026^{* * *}$ & $0,045 * * *$ & $-0,006$ & $0,461 * * *$ & $0,050 * * *$ & $-0,040 * *$ & $-0,009$ & 0,275 \\
\hline $\mathrm{C} 23$ & 0,013 & 0,033 & $-0,013$ & $0,921 * * *$ & $-0,050 *$ & $0,103 * * *$ & 0,026 & 0,331 \\
\hline C24 & 0,008 & $0,065 * * *$ & $-0,009$ & $0,641 * * *$ & $-0,055^{* *}$ & 0,004 & $-0,064 * * *$ & 0,290 \\
\hline $\mathrm{C} 25$ & $0,012 *$ & 0,01 & $0,060 * * *$ & $0,908 * * *$ & 0,007 & $0,048 * * *$ & $-0,028 *$ & 0,445 \\
\hline $\mathrm{C} 26$ & $-0,021 * * *$ & $-0,051 * * *$ & $0,049 * * *$ & $0,313 * *$ & $0,052 * * *$ & $-0,019$ & $-0,008$ & 0,517 \\
\hline $\mathrm{C} 27$ & $0,019 * * *$ & $-0,016$ & $0,051 * * *$ & $0,786 * * *$ & $-0,035^{* *}$ & $0,050 * * *$ & $-0,026^{*}$ & 0,469 \\
\hline C28 & $0,027 * * *$ & 0,001 & $0,059 * *$ & $1,111 * * *$ & $-0,068 * * *$ & $-0,055^{* *}$ & $-0,075 * * *$ & 0,600 \\
\hline C29 & $0,025 * * *$ & $0,021 *$ & $-0,006$ & $0,917 * * *$ & $-0,019$ & $0,055^{* * *}$ & $-0,046 * * *$ & 0,464 \\
\hline C30 & $0,023 * * *$ & 0,001 & 0,008 & $0,517 * * *$ & $0,032 * *$ & 0,02 & 0,004 & 0,173 \\
\hline C31 & $0,031 * * *$ & $-0,004$ & $-0,01$ & $0,488 * * *$ & $-0,009$ & $0,068 * * *$ & $-0,015$ & 0,193 \\
\hline C32 & $0,013 * *$ & $-0,017$ & $-0,007$ & $0,567 * * *$ & $-0,037 * *$ & $-0,023$ & $-0,011$ & 0,442 \\
\hline
\end{tabular}

Fonte: elaborado pelo autor. $* * *$ Significativo a $0,01 . * *$ Significativo a 0,05 . $*$ Significativo a 0,10 .

Apesar da melhora dos coeficientes de determinação no modelo de seis fatores, salienta-se que há ainda parte das variações dos retornos não captadas pelo modelo, mas ressalta-se que este modelo consegue captar melhor as variações dos retornos do que o modelo de cinco fatores de FF na amostra brasileira, já que em 27 das 32 carteiras houveram incrementos nos coeficientes de determinação desse modelo. Por fim, pode-se confirmar a 
pergunta de pesquisa quanto a presença da variável macroeconômica para melhorar a explicação das variações dos retornos. Além disso, as variações dos retornos em excesso das carteiras, em sua maioria, podem ser explicadas pelos fatores de risco prêmio de mercado, tamanho, book-to-market, rentabilidade e investimento.

\section{CONCLUSÕES}

Este trabalho teve o objetivo de verificar o impacto da inclusão de um fator de risco macroeconômico no modelo de cinco fatores de FF (2015). O modelo de cinco fatores introduziu a rentabilidade e o investimento no modelo de três fatores para explicar as variações dos retornos das carteiras de investimentos. $\mathrm{Na}$ análise empírica no mercado americano, concluiu-se que este modelo melhorou significativamente a explicação das variações dos retornos dos ativos.

Para Fama (1990), os retornos dos ativos e as variáveis macroeconômicas estão conectadas pelo fluxo de caixa descontado das empresas, cuja taxa de desconto contém expectativas acerca dos agregados econômicos. Por sua vez, Dimson et al. (2003) e Ritter (2005) encontraram relação significativa entre o crescimento do PIB e os retornos das ações, mas, tal relação foi negativa. Porém, para Wade e May (2013), outros aspectos podem ajudar a desvendar essa relação, como inflação, ciclo econômico e expectativa do PIB no futuro. Assim, este estudo então desenvolveu um fator de risco, baseado nas variáveis macroeconômicas, para ser incluído no modelo de cinco fatores de FF (2015), com o objetivo de captar parte das variações dos retornos dos ativos. Tal fator, o de risco macroeconômico (Crescimento) estabelece uma relação entre o crescimento da receita e o crescimento do PIB de mercado, visto que ambas as variáveis estão relacionadas, como afirmam Andrade e Melo (2016).

Foram construídas 32 carteiras de investimentos, confirmando-se a significância estatística de todos os fatores de risco na maioria das carteiras, com destaque para o fator prêmio de mercado, o fator tamanho e o fator crescimento. A relação encontrada entre os retornos em excesso dos ativos e as variáveis foi em grande parte crescente, com o prêmio de mercado, book-to-market, rentabilidade e crescimento; e decrescente, com tamanho e investimento. Vale salientar ainda que nesta pesquisa não foi identificada a redundância do fator de risco book-to-market, onde tal fator explica variações dos retornos diferentes dos fatores rentabilidade e investimento. 
Em relação aos coeficientes de determinação das regressões, comparando os quatro modelos analisados, observou-se que à medida o modelo inclui a variável macroeconômica no modelo de cinco fatores de Fama e French (2015), a explicação das variações dos retornos das carteiras aumenta, tendo como menor valor 0,139 e chegando até 0,709 de poder de explicação. Além disso, tal variável foi significativa em 19 das 32 carteiras de investimento, "perdendo" somente para a variável tamanho e o prêmio de mercado, sendo possível então inferir que a análise proposta no mercado nacional identifica a presença de um fator de risco macroeconômico que capta as variações dos retornos dos ativos.

Dentre as limitações da pesquisa estão a quantidade de ativos utilizados na análise, que comparativamente com o trabalho de FF (2015) no mercado americano, foram poucas, tendo em vista que o desenvolvimento do mercado acionário nacional ainda é recente, o que contribuiu para que algumas carteiras ficassem vazias. Por sua vez, como sugestão para estudos futuros, recomenda-se a utilização do novo fator de risco em mercados internacionais.

\section{REFERÊNCIAS}

DE ANDRADE, Jucimar Casimiro; DE SOUZA MELO, André. Causalidade entre Variáveis Macroeconômicas e a Receita Bruta: Uma Análise Utilizando Vetores Autorregressivos (VAR). Revista Evidenciação Contábil \& Finanças, v. 4, n. 3, p. 6-29, 2016.

CARHART, Mark M. On persistence in mutual fund performance. The Journal of Finance, v. 52, n. 1, p. 57-82, 1997.

DIMSON, Elroy; MARSH, Paul; STAUNTON, Mike. Global evidence on the equity risk premium. Journal of Applied Corporate Finance, v. 15, n. 4, p. 27-38, 2003.

FAMA, Eugene F. Stock returns, expected returns, and real activity. The Journal of Finance, v. 45, n. 4, p. 1089-1108, 1990.

FAMA, Eugene F.; FRENCH, Kenneth R. Common risk factors in the returns on stocks and bonds. Journal of Financial Economics, v. 33, n. 1, p. 3-56, 1993.

FAMA, Eugene F.; FRENCH, Kenneth R. A five-factor asset pricing model. Journal of Financial Economics, v. 116, n. 1, p. 1-22, 2015.

GUJARATI, Damodar N.; PORTER, Dawn C. Econometria Básica. Porto Alegre: Bookman, 2011.

HOU, Kewei; XUE, Chen; ZHANG, Lu. Digesting anomalies: An investment approach. The Review of Financial Studies, v. 28, n. 3, p. 650-705, 2015.

REAd | Porto Alegre - Vol. 24 - No 3 - Setembro / Dezembro 2018 - p. 269-293 
Instituto Brasileiro de Geografia e Estatística. (2016). Disponível em:

http://www.ibge.gov.br/. Vários acessos.

JEGADEESH, Narasimhan; TITMAN, Sheridan. Returns to buying winners and selling losers: Implications for stock market efficiency. The Journal of Finance, v. 48, n. 1, p. 65 91, 1993.

LINTNER, John. The valuation of risk assets and the selection of risky investments in stock portfolios and capital budgets. Review of Economics and Statistics, v. 47, n. 1, p. 13-37, 1965.

MARKOWITZ, Harry. Portfolio selection. The Journal of Finance, v. 7, n. 1, p. 77-91, 1952.

MLADINA, Peter. The Enigma of Economic Growth and Stock Market Returns. Northern Trust Corporation, 2016.

MUSSA, Adriano; FAMÁ, Rubens; DOS SANTOS, José Odálio. A adição do fator de risco momento ao modelo de precificação de ativos dos três fatores de Fama \& French aplicado ao mercado acionário brasileiro. REGE Revista de Gestão, v. 19, n. 3, p. 431-447, 2012.

NODA, Rafael Falcão; MARTELANC, Roy; KAYO, Eduardo Kazuo. O Fator de Risco Lucro/Preço em Modelos de Precificação de Ativos Financeiros. Revista Contabilidade \& Finanças, v. 27, n. 70, p. 67-79, 2016.

NOVY-MARX, Robert. The other side of the value: The gross profitability premium.

Journal of Financial Economics, v. 108, p. 1-28, 2013.

RITTER, Jay R. Economic Growth and Equity Returns. Pacific-Basin Finance Journal, v. 13, n. 5, p. 489-503, 2005.

SCHWERT, William G. Stock returns and real activity: A century of evidence. The Journal of Finance, v. 45, n. 4, p. 1237-1257, 1990.

SHARPE, W. Capital asset prices: A theory of market equilibrium under conditions of risk. Journal of Finance, v. 19, p. 425-442, 1964.

WADE, Keith; MAY, Anja. GDP growth and equity market returns. Schroder Investment Management North America Inc. 2013. 